\title{
Oral HPV prevalence in general healthy dental patients and patients with oral and oropharyngeal neoplasms in Bulgaria
}

\author{
Assya Krasteva ${ }^{1}$, Atanas lliev ${ }^{2}$ Julian Rangachev ${ }^{2}$, \\ Daniel Markov ${ }^{1}$, Jordan Galabov ${ }^{1}$, Svetoslav \\ Slavkov ${ }^{3}$, Nikolay Yanev ${ }^{3}$
}

1. Department of Oral and Imaging diagnostics, Faculty of Dental medicine, Medical University - Sofia, Bulgaria;

2. Department of Otorhinolaryngology, Faculty of Medicine Medical University - Sofia, Bulgaria;

3. Specialized Hospital for Active Treatment in Oral and Maxillofacial Surgery - Sofia, Bulgaria;

\begin{abstract}
The attention of oncologists and maxillo-facial specialists has been focused on the relation between HPVs and oral carcinogenesis.

Oral HPV infection has been identified as an independent risk factor for oral squamous cell cancer. Over 150 subtypes of HPV have been identified; more than 40 types of HPVs infect the anogenital region and oral cavity. It has been predicted $f$ this that tendency continue this virus will become more wide spread. By 2020, HPV - associated tumors of the throat will surpass the incidence of cervical cancer as the leading HPV -induced neoplasm. It is highly recommended that each patient with a suspicious lesions in the oral cavity should be tested for HPV.
\end{abstract}

We aimed to investigate the presence of HPV in of healthy individuals and in biopsy tissue of patients with oral and oropharyngeal neoplasms.

Keywords: Human Papillomavirus, HPV, oral cancer, oropharyngeal cancer, prevalence 


\section{Introduction}

Oral cancer is the sixth most common malignancy in the world (1).

Human papillomaviruses (HPV) constitute the most widely spread sexually transmitted viral infection world-wide. In about $1 \%$ of the cases, a continuing HPV infection can lead to the appearance of precancerous conditions. In a subsequent carcinoma progression, different types of cancer can develop cervical, rectal, penile, oral, throat, laryngeal, etc. More than 200 HPV types have been established, with at least 25 found in lesions in the oral cavity (2.3).

HPV is also classified as cutaneous or mucosal tropism. The cutaneous types are associated with skin lesions. In contrast, mucosal types infect the anogenital tract and upper aero and digestive tract and include HNSCC, OPSCC, and oral cancer. Mucosal types can be subdivided into low-risk and high-risk types based on their oncogenic potential. The most relevant low-risk types are HPV $6,11,40,42,43,44$, $54,61,70$, and 72 . HPV 31, 33, 35, 52, 58, and 67 are known to be moderate to high-risk. The most highrisk types are HPV 16 and 18 (4).

The attention of specialists in the field has been focused on the relation between HPVs and oral carcinogenesis. It is highly recommended that each patient with a suspicious lesions in the oral cavity should be tested for HPV.

\section{Aim}

To investigate the presence of HPV in the saliva of healthy people and in neoplastic tissues of patients with oral and oropharyngeal neoplasms.

\section{Material}

A 244 patients have been tested for HPV in 2014 and 2015. The patients were divided in two groups:

Group A: 196 (130 women and 66 men) random dental patients aged from 11 to 78 years. They had neither anamnestic data for a neoplasm nor neoplasms in the maxillo-facial area. The average age of the male subjects was $45 \pm 13.8$ years and of the female subjects was $50 \pm 13.6$ years. The patients were tested for HPV in saliva. Saliva samples were collected in laboratory Synevo in order to avoid errors in the pre-analytical stage.

Group B: 48 (16 women and 32 men) random patients with oral and oropharyngeal neoplasms aged from 35 to 89 years. The average age of the male subjects was $56 \pm 11.7$ years and of the female subjects was $55 \pm 10.6$ years. The presence of HPV was tested in biopsy tissues of neoplasms. 


\section{Methods}

- PCR method with colorimetric detection was used for detection of HPV types in saliva and tissues; genotyping was performed using a strip containing specific probes.

- Each patient completed an informed consent form and a questionnaire on the cancer cases in their familes and issues related to the spread of the virus.

- TNM system was used for the characterization of neoplasms in the maxillofacial area

\section{Results}

A. Human virus papilloma in whole unstimulated saliva in healthy individuals.

B.

$19 \%$ of the patients were up to 39 years, $30 \%$ were from 40 to 59 years and $51 \%$ were over 60 years (Fig. 1).

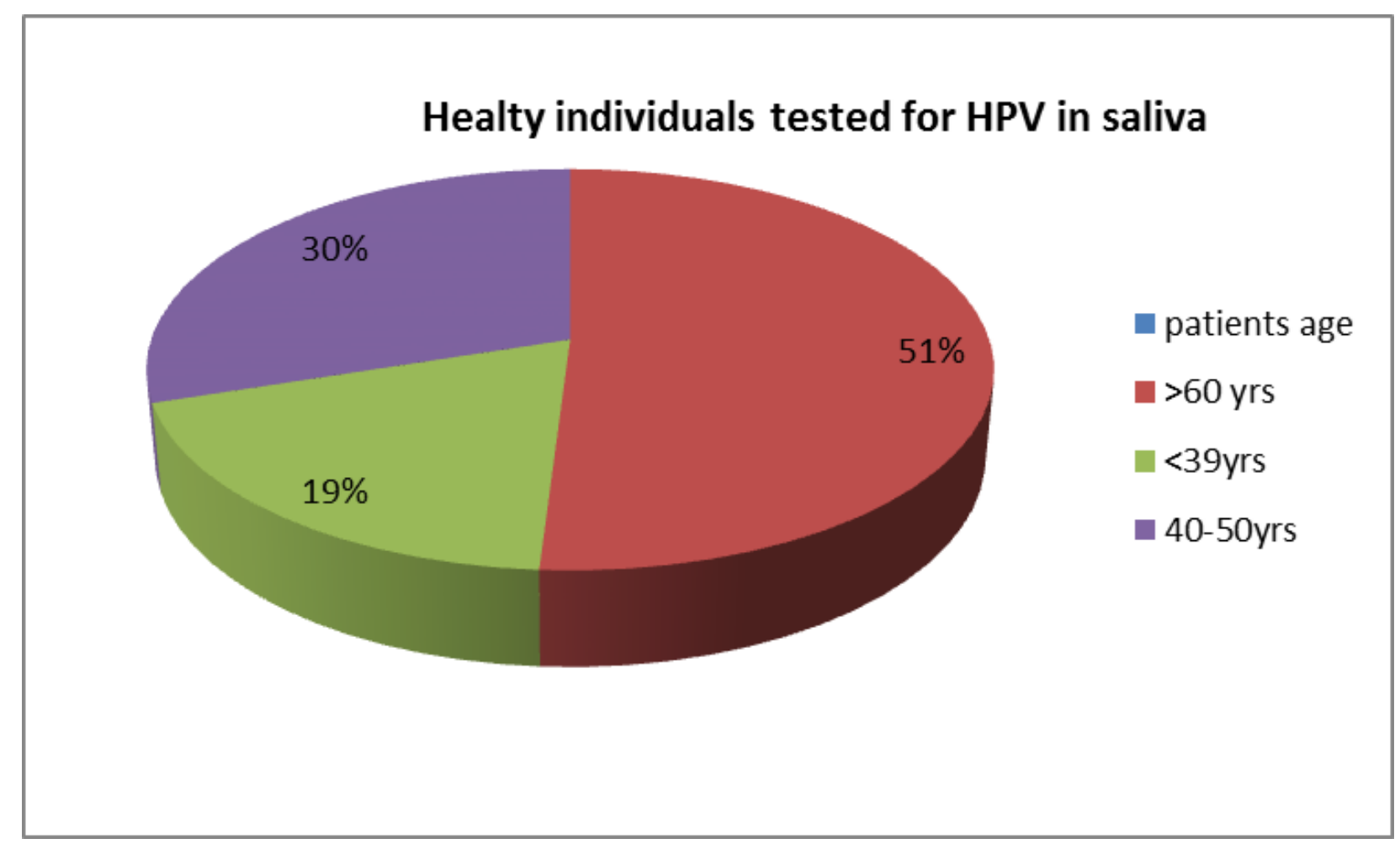

Figure 1. Healthy dental patients tested for HPV in saliva

HPV was found in whole unstimulated saliva in 10 general healthy individuals $-5.1 \%$ of the tested people (Table 1). 
Table 1. Healthy individuals with HPV positive saliva

\begin{tabular}{|l|l|l|l|l|}
\hline Age (years) & Sex & HPV Genotype & HPV Genotype & HPV Genotype \\
\hline 32 & male & $\mathbf{4 2}$ & & \\
\hline 35 & male & $\mathbf{1 6}$ & & \\
\hline 42 & male & $\mathbf{1 6}$ & $\mathbf{5 2}$ & $\mathbf{6 6}$ \\
\hline 52 & female & $\mathbf{1 6}$ & & \\
\hline 53 & female & $\mathbf{1 6}$ & & \\
\hline 55 & female & $\mathbf{1 6}$ & $\mathbf{6 6}$ & \\
\hline 60 & female & $\mathbf{1 6}$ & & \\
\hline 63 & female & $\mathbf{1 6}$ & & \\
\hline 64 & female & $\mathbf{1 6}$ & $\mathbf{5 2}$ & \\
\hline 75 & male & $\mathbf{1 6}$ & $\mathbf{6 6}$ & \\
\hline
\end{tabular}

The HPV positive general healthy patients were 4 men (6.06\%) and 6 women (4.6\%). The high-risk genotype 16 was found in 9 patients - 90\% of the cases. In 4 cases, there are 2 genotypes - $40 \%$ and in 1 case 3 genotypes.

The older the patients the higher the frequency of HPV in saliva. It rose from $3 \%$ to $7.8 \%$ (Fig. 2).

Figure 2. Healthy individuals - carriers of HPV in whole unstimulated saliva

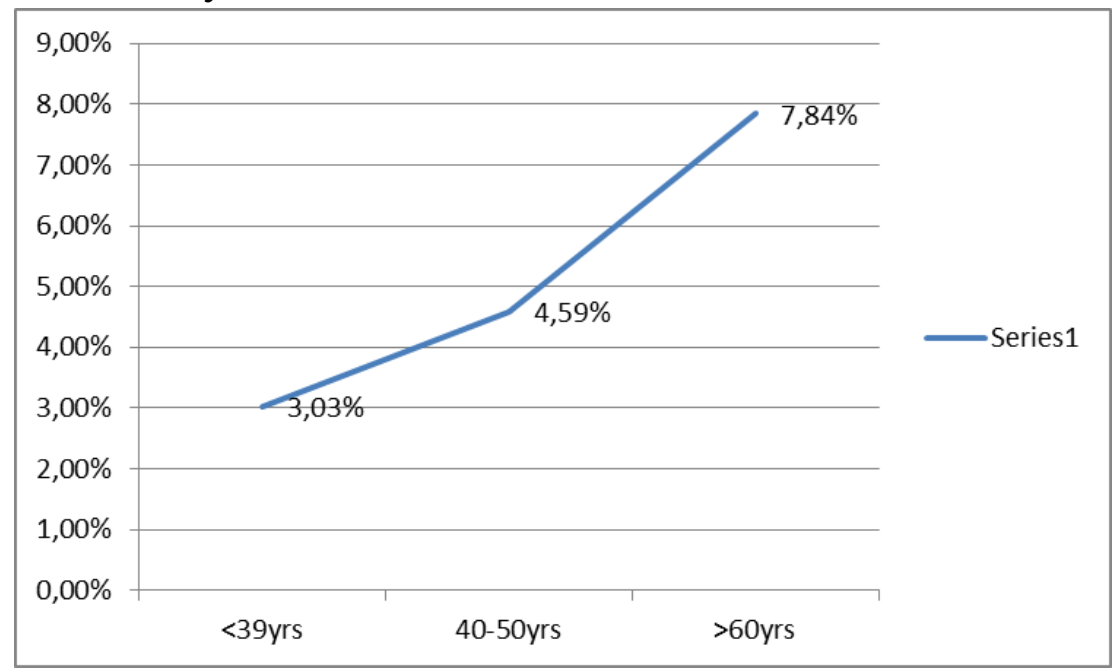


We didn't detect HPV in saliva in any patient under the age of 30 , representing $9 \%$ of those surveyed.

\section{B. Human papillomavirus in biopsy material from oral and oropharyngeal neoplasms}

The characteristics of the observed neoplasms are presented in Table 2.

Table 2. Neoplasms, examined for HPV in biopsies

\begin{tabular}{|l|l|l|l|}
\hline Neoplasm & Men & Women & Total \\
\hline Ca linguae, gingivae et labii oris (spinocellulare) & 4 & 5 & 9 \\
\hline Leucoplakia & 0 & 6 & 6 \\
\hline Ca laryngis & 21 & 2 & 23 \\
\hline Papilloma & 2 & 1 & 3 \\
\hline Papillofibroma & 3 & 1 & 4 \\
\hline Tu pharynges & 2 & 1 & 3 \\
\hline Total & 32 & 16 & 48 \\
\hline
\end{tabular}

In $11 \%$ of the primary tumor the largest diameter of the tumor was up to $2 \mathrm{~cm}$ - corresponding to T1.

In 22\%, the primary tumor was greater than $4 \mathrm{~cm}$, corresponding to T3. Most patients were in T4 stage (a tumor growing in adjacent tissues) - 67\%. In 7.2\% of the patients N2 stage (metastasis up to $6 \mathrm{~cm}$ in ispsilatetal lymph nodes or bilaterally) was established.

$50 \%$ of the patients had moderately differentiated squamous cell carcinomas, $20 \%$ had well-differentiated and $20 \%$ had low-differentiated carcinoma. Secondary recurrent carcinoma was present in $10 \%$.

Table 3. Summarized anamnestic data of patients with oral neoplasms obtained from an anonymous survey

\begin{tabular}{|l|l|l|l|}
\hline Group Characteristics & yes & no & No answer \\
\hline Homosexual orientation & $10.5 \%$ & $63.2 \%$ & $26,3 \%$ \\
\hline Having more than 5 sex partners & $26.3 \%$ & $37 \%$ & 36.8 \\
\hline Using paid sex services & $5 \%$ & $63 \%$ & $32 \%$ \\
\hline Maxillo-facial neoplasms in the family & $10.5 \%$ & $89.5 \%$ & \\
\hline Smoking & $72 \%$ & $28 \%$ & \\
\hline Alcohol abuse & $39 \%$ & $61 \%$ & \\
\hline
\end{tabular}

* $22.2 \%$ of patients announced that they smoked $10-20$ cigarettes a day

** $11 \%$ consumed alcohol in significant amounts (more than $50 \mathrm{ml} /$ daily) 
HPV was found in neoplastic tissues in 11 patients (22.9\%) - in 2 women (12.5\%) and 9 men (28.1\%) (Table 4).

Table 4 .HPV positive tissue in oral neoplasms

\begin{tabular}{|l|l|l|l|}
\hline $\begin{array}{l}\text { Age } \\
\text { (years) }\end{array}$ & man 1/woman $\mathbf{2}$ & HPV genotype & Diagnosis \\
\hline 35 & 1 & 11 & Cancer of the tongue \\
\hline 59 & 1 & 6 & Cancer of the tongue \\
\hline 51 & 2 & 11 & Cancer of the tongue \\
\hline 73 & 1 & 6 & Larynx cancer \\
\hline 49 & 1 & 6 & Larynx cancer \\
\hline 52 & 1 & 6 & Larynx cancer \\
\hline 64 & 1 & 16 & Larynx cancer \\
\hline 58 & 1 & 16 & Larynx cancer \\
\hline 64 & 1 & 11 & Larynx cancer \\
\hline 57 & 2 & 6 & Pharynx cancer \\
\hline 50 & 1 & 6 & Pharynx cancer \\
\hline
\end{tabular}

Genotype 16 was detected in two patients, genotypes 11 in 3 and genotype 6 in 6 patients (Fig.3).

Figure 3. HPV types in the tissues of patients with oral neoplasms

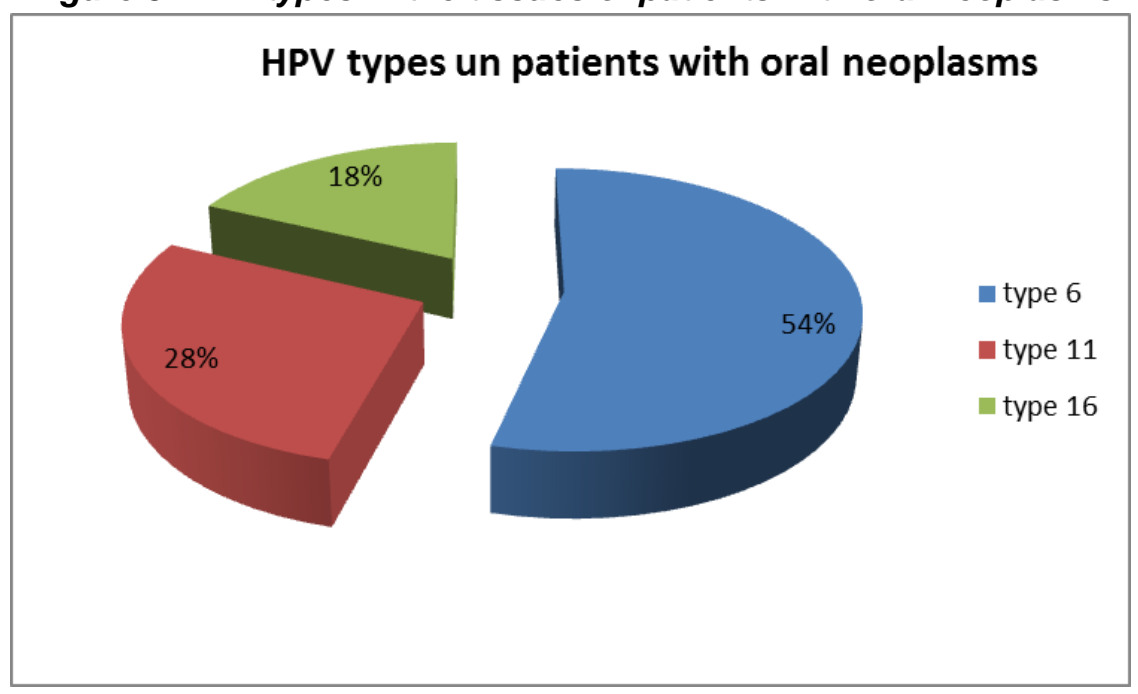

The relation between HPV in in biopsy tissue and the age of patients as follows: $25 \%$ up to 39 years old patients, $24 \%$ in the $40-59$ age range, and $16 \%$ - over 60 years old patients. 


\section{Discussion}

Globally, about 5 to $10 \%$ of the world population is infected with HPV. Usually the natural immunity controls the infection (5).

Until recently, approximately $20 \%$ of oral cancers and $60 \%$ to $80 \%$ of oropharyngeal carcinomas were attributable to HPV infection. In 2012, the International Agency of Research of Cancer (IARC) declared that there was sufficient data to associate a subtype of HPV 16 with oral cancers (6). 24 types of HPV have been associated with benign lesions in the oral cavity: $1,2,3,4,6,7,10,11,13,16,18,30,31,32$, $33,35,45,52,55,57,59,69,72$ and 73. 12 types with malignant lesions: 2, 3, 6, 11, 13, 16, 18, 31, 33, 35,52 and $57(7,8)$.

We detected HPV in the saliva of 5\% of healthy dental patients and $23 \%$ in the tissues of the patients with oral and oropharyngeal neoplasms, which is 4 times more frequent. After new oropharyngeal infections, permanent virus presence remains in only $10 \%$ of the cases. Some centers account for more than $70 \%$ of oropharyngeal cancer associated with HPV infection, and others only for $20 \%$ (5). We found HPV in saliva in $6 \%$ of men, compared to $4.6 \%$ in women.

According to the date of USA scientists about $10 \%$ of men and $3.6 \%$ of women allows have active HPV in the oral cavity.

Biopsy materials reveal gender difference in HPV incidence. Men are infected twice more often than women. While the risk of HPV in women decreases with age, men are at a higher risk of getting new HPV infections throughout their lives $(9,10)$.

We did not record HPV in saliva in any patient under 30 years of age. The age of the positive patients varies from 32 to 75 years.

In our study $90 \%$ of HPV-positive saliva were carriers of HPV 16 oncogenic genotype 4 of the patients (40\%) have two genotypes simultaneously, and in one case there are three genotypes.

In contrast to saliva data we found 2 positive patients with HPV 16, 3 with HPV positive genotype 11 and 6 with HPV 6.

It is now assumed that a large percentage of cervical and vulvar carcinomas are due to infection with HPV16 and HPV18 (11).

HPV in cervical cancer is associated with so-called HPV oncogenes, as we have found in the saliva of the healthy ones rather than in the tissues of the patients. The discovery of HPV16 precedes the onset of oropharyngeal cancer. Binding to other HPV types including $\mathrm{\gamma} 11-$ and $\mathrm{Y} 12-\mathrm{HPV}$ and $\beta 1-\mathrm{HPV}-5$ type suggest a broader role for HPV in the aetiology of squamous cell carcinomas in the maxillofacial area (12). In this respect, our results are close to this idea.

There is limited evidence for HPV in laryngeal cancer (6). In our larynx cancer patients, we found $26 \%$ of HPV in biopsy tissue. The half of our laryngeal carcinoma patients were with HPV type 6 and 1/3 HPV 16 (tabl 4). 
Table 5. Studies on HPV prevalence among cases of hypopharyngeal or laryngeal cancer in Europe

\begin{tabular}{|c|c|c|c|}
\hline Study & $\begin{array}{c}\text { No. } \\
\text { Tested }\end{array}$ & $\begin{array}{l}\text { HPV } \\
\text { prevalence } \\
\%\end{array}$ & $\begin{array}{l}\text { Prevalence of } 5 \text { most frequent HPVs } \\
\text { HPV type (\%) }\end{array}$ \\
\hline Anderson 2007 (UK) & 64 & 0.0 & \\
\hline Snietura 2011 (Poland) & 65 & 0.0 & \\
\hline Morshed 2008 (Poland) & 93 & 35.5 & $\begin{array}{l}\text { HPV16 (30.1\%) HPV } 18 \text { (6.5\%) HPV } 33 \\
(5.4 \%)\end{array}$ \\
\hline $\begin{array}{l}\text { Boscolo-Rizzo } 2009 \\
\text { (Italy) }\end{array}$ & 45 & 4.4 & HPV 16 (4.4\%) \\
\hline Badaracco 2007 (Italy) & 30 & 16.7 & HPV 16 (10.0\%) HPV 6 (6.7\%) \\
\hline Duray 2011 (Belgium) & 59 & 79.7 & $\begin{array}{l}\text { HPV } 16 \text { (62.7\%) HPV } 18 \text { (16.9\%) HPV } 51 \\
(8.5 \%) \text { HPV } 33 \text { (5.1\%) HPV } 66 \text { (5.1\%) }\end{array}$ \\
\hline $\begin{array}{l}\text { Hoffmann } 2009 \\
\text { (Germany) }\end{array}$ & 27 & 29.6 & HPV $16(14.8 \%)$ \\
\hline $\begin{array}{l}\text { Personal data } 2016 \\
\text { (Bulgaria) }\end{array}$ & 11 & 22.9 & HPV 6 (54\%) HPV 11 (28\%) HPV 16 (18\%) \\
\hline
\end{tabular}

We chose seven communications in the last 10 years in Europe and it appears that the HPV prevalence among cases of hypopharyngeal or laryngeal cancer ranges from 0 to $80 \%$. Even in the same country there are large differences from article to article (Poland, Italy). For HPV types, HPV 16 was found from $4.4 \%$ to $63 \%$ of the cases. HPV 6 was reported only once and at $6.7 \%$, whereas we found it in half of our patients.

There are three other papers that report HPV 6 - Koskinen 2003 (Finland) HPV 6 (10.7\%), Badaracco 2000 (Italy) HPV 6 (18.2\%), Badaracco 2007 (Italy) ) And Alvarez Alvarez 1997 Spain) HPV 16 (5.7\%)

\section{HPV burden in the head and neck}

The last evaluation of the International Agency for Research in Cancer (IARC) on the carcinogenicity of HPV in humans concluded that (a) there is enough evidence for the carcinogenicity of HPV type 16 in the oral cavity, oropharynx (including tonsil cancer, base of tongue cancer and other oropharyngeal cancer sites), and (b) limited evidence for laryngeal cancer (6).

There is increasing evidence that HPV-related oropharyngeal cancers constitute an epidemiological, molecular and clinical distinct form as compared to non HPV-related ones. Some studies indicate that the most likely explanation for the origin of this distinct form of head and neck cancers associated with HPV is a sexually acquired oral HPV infection that is not cleared, persists and evolves into a neoplastic lesion. 
The most recent data estimate that $25.6 \%$ of all oropharyngeal cancers are attributable to HPV infection with HPV16 being the most frequent type (13). In this section, the HPV burden in the head and neck in the World is presented.

The presence of HPV in saliva reflects the presence of the virus in other biological fluids and raises the question of the pathway for infection. Jong-Myon Bae associate HPV with lung cancer in non-smokers and women in Korea and recommend preventation (14).

HPV was found in $16.4 \%$ of the exhaled air of 89 cancer patients with lung carcinoma, mostly HPV 16 and HPV 31 (15).

The period from the first oral HPV infection to the onset of neoplasm is no known, but it takes many years. Some people have an infection of 15 years or more before developing a tumor process (3).

Of the patients with oral and oropharyngeal neoplasms, over 5 sexual partners reported $26.3 \%, 10.5 \%$ reported homosexual orientation, and $5 \%$ used sexually paid services, suggesting that at least $1 / 4$ of our patients had a higher risk of sexual intercourse with HPV. Whether these are those patients where we established HPV cannot be understood because the survey was anonymous.

In a longitudinal study of 222 men and their partners, oral and genital samples were examined. Oral HPV prevalence among males is $7.2 \%$ and is higher for males when they are not monogamous (17.9\%) or have partner with oral (28.6\%) and / or genital (11.5\%) HPV infection. There were no HPV infections in males who had a partner without oral or genital HPV, those who were monogamous or those who had never smoked (10). One defect of our study is the lack of data on the sexual life of routine dental patients.

In our study, the age of patients with oral and oropharyngeal neoplasms and routine dental patients is similar. With age, there is an increasing incidence of HPV infection in saliva, as in people over 60 years the frequency is almost $8 \%$. We did not observe this phenomenon in neoplastic patients.

How people get infected with oral HPV is widely discussed in the medical research topic. Some studies have shown that the virus can be transferred through oral sex to a person who has genital HPV infection, while others claim the infection can spread by kissing with a person with oral HPV infection and lately there are more bold claims to carry of the virus in simple contact (16).

\section{Conclusion}

In total unstimulated saliva, healthy HPV was found in 5\%, while in neoplastic tissue - $23 \%$. Undoubtedly, in the neoplastic tissue, the incidence of the virus is much greater - about 5 times, more commonly in male subjects, especially in the tissue. The incidence of HPV infection in saliva, but not in neoplasms, increases with age. Very interesting is the fact that there is a difference in the genotypic frequency between saliva, which contains high risk oncogenic types and the tissue dominated by "low risk" genotypes. 


\section{References}

1. Sun JR, Kim SM, Seo MH, et al. Oral cancer incidence based on annual cancer statistics in Korea. J Korean Assoc Oral Maxillofac Surg 2012;38:20-28.

2. Krasteva, A, lliev, A, Rangachev, et al. HPV status of Bulgarian patients with oropharyngeal and oral carcinomas. Oral Diseases 2016;22:2.

3. Krasteva A, Dobreva A, Galabov V, et al. HumanPapillomaviruses, Herpes Viruses and Oral Neoplasms. MedInform 2015; 1:131- 141.

4. Soung Min Kim. Human papilloma virus in oral cancer J Korean Assoc Oral Maxillofac Surg 2016:42:6: 327-336.

5. Vlantis, AC. Human Papilloma Virus and Oropharyngeal Carcinoma - Lessons from History. Chin J Dent Res 2016;19:1:9-16.

6. IARC Working Group on the Evaluation of Carcinogenic Risks to Humans. IARC monographs on the evaluation of carcinogenic risks to humans: IARC monographs, volume 100B. A review of human carcinogens. B. Biological agents. Lyon: International Agency for Research on Cancer 2012; 278-280

7. Bouda M, Gorgoulis VG, Kastrinakis NG, et al. "High risk" HPV types are frequently detected in potentially malignant and malignant oral lesions, but not in normal oral mucosa. Mod Pathol 2000;13:644-653.

8. Kojima A, Maeda $\mathrm{H}$, Sugita $\mathrm{Y}$, et al. Human papillomavirus type 38 infection in oral squamous cell carcinomas. Oral Oncol 2002;38:591-596.

9. Giuliano, AR, et al. Incidence and Clearance of Genital Human Papillomavirus Infection in Men (HIM): A Cohort Study. Lancet 2011;377:9769:932-940.

10. Giuliano, AR, Gillison, M. Human Papillomavirus Infection And Cancer Risk. Intervew, 2011.

11. Badoual, C, Tartour, E, Roussel, H, et al. HPV (Human Papilloma Virus) implication in other cancers than gynaecological. Rev Med Intern 2015; 36:8:540-547.

12. Agalliu I, Gapstur S, Chen Z, et al. Associations of Oral $\alpha-, \beta-$, and $\gamma$-Human Papillomavirus Types With Risk of Incident Head and Neck Cancer. JAMA Oncol 2016.

13. de Martel C, Ferlay J, Franceschi S, et al. Global burden of cancers attributable to infections in 2008: a review and synthetic analysis. Lancet Oncol 2012;13:6:607-615.

14. Bae, JM, Kim, EH. Human papillomavirus infection and risk of lung cancer in never-smokers and women: an 'adaptive' meta-analysis. Epidemiol Health 2015; 37: e2015052.

15. Carpagnano, GE, Koutelou, A, Natalicchio, MI, et al. HPV in exhaled breath condensate of lung cancer patients. Br J Cancer 2011;105:8:1183-1190.

16. Dahlstrom, KR, Burchell, AN, Ramanakumar, AV, et al. Sexual transmission of oral human papillomavirus infection among men. Cancer Epidemiol Biomarkers Prev, Dec, 2014;23:12:2959-2964.

\section{Corresponding author:}

Assya Krasteva,

Faculty of Dental Medicine,

Medical University - Sofia, Bulgaria

Department of Imaging and Oral diagnostics

Sofia 1000, bul. Sveti Georgi Sofiiski 1, Bulgaria

Email: asyakrasteva@gmail.com 